\title{
Study of KAP with regard to taking folic acid supplements and factors affecting the recommendation and prescription of those supplements among obstetricians and specialists in women's health in six provinces of Northern China, 2009
}

\author{
Ting Li ${ }^{1}$, Jun Zhu' ${ }^{2}$ Ziqian Zeng ${ }^{1}$, Yanping Wang ${ }^{2}$, Juan Liang ${ }^{2}$ Ping Yuan ${ }^{1, *}$ \\ ${ }^{1}$ Department of Epidemiology, West China School of Public Health, Sichuan University, Chengdu, China; \\ ${ }^{2}$ National Center for Birth Defects Monitoring of China, West China Women's and Children's Hospital, Sichuan University, \\ Chengdu, China.
}

Summary

\begin{abstract}
Taking folic acid (FA) supplements reduces the risks of neural tube defects (NTDs) in early pregnancy. Obstetricians and specialists in women's health play important roles in promoting FA intake. However, surveys on their knowledge of, attitudes toward, and behavior regarding giving FA to pregnant women are limited. A cross-sectional study was conducted with 5,860 obstetricians and specialists in women's health using a self-administered questionnaire to collect information on participants' demographic characteristics and their knowledge of and attitudes toward and practices related to taking FA supplements. Chi-square analysis was used for rate comparison while logistic regression analysis was performed to predict influencing factors. For items on knowledge about FA and taking FA supplements the overall correct response rate was $60.3 \%(24,235 / 40,173)$. Questions about related practices and attitudes were correctly answered for the most part (more than $\mathbf{9 0} \%$ ), but participants were less likely to follow the practice of prescribing FA tablets to women planning a pregnancy while working (77.2\%). Statistical analysis indicated that the "Level of facility where the participant works" and "Rate of correct responses on a test of knowledge" were the main factors affecting participants' recommendation to take FA while "Job title", "Amount of professional work experience", and "Rate of correct responses on a test of knowledge" were the main factors affecting participants' prescription of FA. In conclusion, participants had a good deal of knowledge about NTDs and FA but the lack of some knowledge possibly led to the relatively low rate of correct behaviors. Therefore, educating obstetricians and specialists in women's health in this regard is crucial.
\end{abstract}

Keywords: Folic acid, folate, neural tube defects, obstetrician

\section{Introduction}

Neural tube defects (NTDs) are some of the most common birth defects since they lead to miscarriages, fetal death, stillbirth, and permanent infant disability.

\footnotetext{
*Address correspondence to:

Dr. Ping Yuan, Department of Epidemiology, West China School of Public Health, Sichuan University, No.16, Sec.3, Renmin South Road, Chengdu 610041, China.

e-mail: yuanp1117@126.com
}

The incidence of these defects is typically $2.3 \sim 2.5$ per 1,000 births in China, but this figure is as high as 6.0 10.0 in some areas according to Birth Defects Monitoring (1). This group of congenital anomalies includes anencephaly, encephalocele, iniencephaly, meningocele, myelomeningocele, myeloschisis, lipomeningocele, and spina bifida.

Folic acid (FA) is a water-soluble vitamin that is closely associated with NTDs (2). FA is not a new drug but is an existing chemical that has been available since the 1950 s. FA has been widely utilized to prevent folate deficiency (3), one of the most common vitamin 
deficiencies among women today. Research has shown that women who consume a low level of folate during pregnancy are at risk of poor pregnancy outcomes, including some birth defects such as NTDs (4). Previous studies confirmed that women of childbearing age should consume at least $0.4 \mathrm{mg}$ of FA daily, especially before or during early pregnancy $(5,6)$. This may not only reduce the risk of NTDs by $50-70 \%$ but may also prevent other major birth defects (7). A large prospective study conducted by American research group found a 64\% lower risk of NTDs in the offspring of women using multivitamins during the first 6 weeks of pregnancy; the offspring of those who took multivitamins containing folic acid had a $73 \%$ lower risk, whereas the offspring of those who took multivitamins without folic acid had only a $7 \%$ lower risk (8). This epidemiological evidence was strengthened by a nonrandomized intervention study carried out in China (9). Periconceptional use of daily supplements containing $0.4 \mathrm{mg}$ of folic acid led to a $79 \%$ reduction in the risk of NTDs in Northern China (with a higher baseline rate of NTDs) and a $41 \%$ reduction in the South (with a much lower baseline rate of NTDs). Consequently, since the early 1990s health authorities in many developed countries have recommended that all women planning pregnancy should consume additional dietary and supplementary FA preconceptionally (10). In 2006, the WHO released a guide on folate fortification to promote folic acid supplements worldwide (11). In 1993, the Chinese Ministry of Health required that all newly married women should take $0.4 \mathrm{mg} /$ day of oral FA supplements from marriage until 3 months after pregnancy; for women living in cities, the schedule was changed to when women began planning their pregnancies. Despite these recommendations and national campaigns, preconceptional intake of additional FA remains very low in some areas of China. A previous survey indicated that the intake rate was $12.1 \%$ and only $4.5 \%$ when used periconceptionally in the northern areas of China, which had a high prevalence of NTDs in 2008 (12).

Obstetricians and specialists in women's health play significant roles in promoting FA intake. Their knowledge of and attitudes toward FA directly affect the use of FA supplements, in turn helping reduce the incidence of NTDs. In April, 2008, the Chinese Ministry of Health implemented its "Project on birth defect interventions in six provinces of Northern China". The project covered a total of 293 impoverished counties in the six provinces of Shanxi, Inner Mongolia, shaanxi, Gansu, Qinghai, and Xinjiang, all of which have a high incidence of NTDs. Northern China faces increased prevalence of NTDs, especially in poor regions. A previous study showed that the prevalence of NTDs in those six provinces was up to $16.0 / 10,000$ births of at least 28 weeks of gestation in 2008 (12). Prevention and treatment of birth defects by steps such as taking FA supplements may be crucial to women in those areas.

In order to provide a scientific basis for enhancing intervention in the form of recommending or prescribing FA supplements, the current study investigated the knowledge, attitudes, and practices (KAP) of obstetricians and specialists in women's health with regard to the addition of small doses FA for childbearing women to prevent NTDs. This study also analyzed factors affecting the behaviors of these obstetricians and specialists in women's health.

\section{Materials and Methods}

\subsection{Participants}

A total of 5,860 obstetricians and specialists in women's health who were involved in county-level projects to prevent birth defects participated in this study. Twenty participants were selected from each of 293 poor counties in six provinces.

\subsection{Survey tools}

A self-administered questionnaire was designed based on a review of the literature. The questionnaire asked about $i$ ) the participants' demographic characteristics such as age, ethnicity, level of education, level of the facility where the participant works, department, job title, and work experience, ii) knowledge about taking FA supplements, such as knowledge about NTDs and FA, and taking FA supplements, iii) attitudes toward taking FA supplements, and $i v$ ) the routine practice of recommending FA supplements.

\subsection{Survey method}

A cross-sectional study was carried out using an anonymous self-administered questionnaire. This study was conducted with the participants' consent.

\subsection{Statistical analysis}

EpiData 3.02 (EpiData Association, Odense, Denmark) was used to develop a study database, and SPSS 16.0 (IBM, Armonk, NY, USA) was used for statistical analysis. Chi-square analysis was used for rate comparison and logistic regression analysis was performed to predict influencing factors. The level of statistical significance was less than 0.05 in this study.

\section{Results}

\subsection{Demographic characteristics}

All 5,860 obstetricians and specialists in women's health received a questionnaire; the response rate was $100 \%$. Incorrectly completed questionnaires were eliminated, 
resulting in 5,739 valid questionnaires (97.9\%). The 5,739 participants had an average age of $35.6 \pm 8.1$ years, and most participants were ages 31-40 (44.0\%) while few were under the age of $20(0.4 \%)$. Most participants belonged to the Han ethnic group (80.1\%). Subjects with an associate degree accounted for $43.6 \%$ of the participants, those with high school or secondary education accounted for $41.1 \%$, and those with undergraduate or higher education accounted for $11.4 \%$. The facility where the participant works was most often a district-level or county-level hospital (61.1\%), followed by a township hospital $(31.6 \%)$ or a municipal hospital (4.6\%). In terms of their job titles, most participants were specialists $(55.8 \%)$ although a few were senior-level or administrators $(4.8 \%)$. Most participants had five or more years of professional work experience (75.2\%).

\subsection{Survey of participants' $K A P$}

Seven questions about NTDs knowledge resulted in a total of 40,173 responses from the 5,739 participants. Of these, 24,235 were correct responses, indicating a correct response rate of $60.3 \%(24,235 / 40,173)$. In particular, awareness of "when NTDs occur" was least often answered correctly, that is, only $27.2 \%$ of participants responded correctly. Nine questions on knowledge about FA and taking FA supplements had 32,656 correct responses, resulting in an overall correct response rate of $63.2 \%(32,656 / 51,651)$. Only $34.1 \%$ participants knew that "women planning to become pregnant and pregnant women-to-be should both take FA supplements", while $37.5 \%$ knew that "taking 0.4 mg of FA each day meets the daily requirement for FA".
With regard to participants' attitudes, more than $90 \%$ correctly answered questions on related practices and attitudes. However, fewer participants prescribed FA tablets to women planning to become pregnant while working (77.2\%) (Table 1).

\subsection{Analysis of factors influencing behavior related to recommending/prescribing FA supplements}

Differences in age, level of education, the level of facility where the participant works, and job title led to different rates of following the practice of "usually recommending that women take FA supplements". Participants of the Han ethnicity were more like to follow the practice than were other ethnic groups; gynecologists/obstetricians were more like to follow the practice than were specialists in women's health. Participants with five years of professional working experience were more likely to answer correctly than those with one to five years; participants with a $60 \%$ overall correct response rate were more likely to correctly answer questions related to knowledge of taking FA supplements than those with a correct response rate of less than $60 \%(p<0.05)$ (Table 2$)$.

Differences in age, level of education, the level of facility where the participant works, and job title led to different rates of following the practice of "routinely prescribing FA tablets to women planning to become pregnant while working". Participants of the Han ethnicity were more like to follow the practice than were other ethnic groups; gynecologists/obstetricians were more like to follow the practice than were specialists in women's health. Participants with five years of

Table 1. Participants' KAP related to taking FA supplements

\begin{tabular}{|c|c|c|}
\hline Index & $\begin{array}{l}\text { Number of participants } \\
\text { with correct responses }\end{array}$ & $\begin{array}{l}\text { Correct response rate } \\
(\%)\end{array}$ \\
\hline \multicolumn{3}{|l|}{ K: Knowledge of NTDs } \\
\hline Definition of NTDs & 5,477 & 95.4 \\
\hline When they typically occur & 1,561 & 27.2 \\
\hline Types of NTDs & 2,232 & 38.9 \\
\hline The most common type of NTDs & 3,325 & 57.9 \\
\hline Prognosis for infants with NTDs & 4,144 & 72.2 \\
\hline Definition of spina bifida & 3,194 & 55.7 \\
\hline Parts of the body commonly affected by spina bifida & 4,302 & 75.0 \\
\hline \multicolumn{3}{|l|}{ K: Knowledge about FA and taking FA supplements } \\
\hline What is FA & 5,041 & 87.8 \\
\hline Main source of human folate & 4,133 & 72.0 \\
\hline Which women should take FA supplements & 1,958 & 34.1 \\
\hline Types of deformity prevented by FA & 5,138 & 89.5 \\
\hline Correct dose of FA for typical women of childbearing age & 4,576 & 79.7 \\
\hline Correct dose of FA for women at risk of having an infant with NTDs & 2,775 & 48.4 \\
\hline Correct way to take FA & 4,913 & 85.6 \\
\hline Correct time to take FA & 1,969 & 34.3 \\
\hline How to ensure a sufficient quality of FA each day & 2,153 & 37.5 \\
\hline \multicolumn{3}{|l|}{ A: Attitudes toward taking FA supplements } \\
\hline Pregnant women should take FA & 5,553 & 96.8 \\
\hline Doctors need to discuss FA with women of childbearing age & 5,556 & 96.8 \\
\hline $\begin{array}{l}\text { Doctors should routinely prescribe FA tablets to women of childbearing age who plan to } \\
\text { become pregnant }\end{array}$ & 5,277 & 91.9 \\
\hline The importance of FA will be explained to every woman of childbearing age in the future & 5,477 & 95.4 \\
\hline \multicolumn{3}{|l|}{ P: Practices with regard to taking FA supplements } \\
\hline You usually recommend that women take FA while working & 5,183 & 90.3 \\
\hline You routinely prescribe FA tablets to women planning to become pregnant while working & 4,430 & 77.2 \\
\hline
\end{tabular}


professional working experience were more likely to answer correctly than those with one to five years; participants with a $60 \%$ overall correct response rate were more likely to correctly answer questions related to knowledge of FA addition than those with a correct response rate of less than $60 \%(p<0.05)$ (Table 3$)$.

Variables with $p<0.20$ in univariate analysis were subjected to multivariate logistic regression analysis; Table 4 shows the coding of variables. With an $\alpha$, the significance level, of 0.05 , the variables in the regression model of the practice of "usually recommending that women take FA supplements" were: ethnicity, level of education, the level of facility where the participant works, job title, professional working experience, and rate of correct responses on a test of knowledge. In conclusion, the higher the level of facility where the participant works, the more likely the participant is to recommend that women take

Table 2. Univariate analysis of participants' behavior of "usually recommending that women take FA supplements"

\begin{tabular}{|c|c|c|c|c|c|}
\hline Variable & Groups of responses & $\begin{array}{l}\text { Number of participants } \\
\text { with correct behaviors }\end{array}$ & $\begin{array}{l}\text { Rate of correct } \\
\text { behaviors }(\%)\end{array}$ & $\chi^{2}$ & $p$-value \\
\hline Age & $\begin{array}{l}\sim 20 \\
\sim 30 \\
\sim 40 \\
40+\end{array}$ & $\begin{array}{r}23 \\
1,446 \\
2,286 \\
1,306\end{array}$ & $\begin{array}{l}95.8 \\
89.9 \\
90.6 \\
90.1\end{array}$ & 1.464 & 0.691 \\
\hline Ethnicity & $\begin{array}{l}\text { Han } \\
\text { Other }\end{array}$ & $\begin{array}{r}4,183 \\
917\end{array}$ & $\begin{array}{l}91.0 \\
86.8\end{array}$ & 17.85 & $<0.05$ \\
\hline Level of education & $\begin{array}{l}\text { Junior high school or lower } \\
\text { Senior high school or secondary school } \\
\text { Junior college } \\
\text { Undergraduate or higher }\end{array}$ & $\begin{array}{r}148 \\
2,125 \\
2,279 \\
603\end{array}$ & $\begin{array}{l}84.1 \\
89.4 \\
91.1 \\
91.8\end{array}$ & 13.14 & $<0.05$ \\
\hline $\begin{array}{l}\text { Level of facility where } \\
\text { the participant works }\end{array}$ & $\begin{array}{l}\text { Village/community } \\
\text { Township } \\
\text { District and county } \\
\text { City } \\
\text { Province }\end{array}$ & $\begin{array}{r}59 \\
1,586 \\
3,244 \\
202 \\
39\end{array}$ & $\begin{array}{l}88.1 \\
87.5 \\
91.7 \\
89.8 \\
90.7\end{array}$ & 25.20 & $<0.05$ \\
\hline Job title & $\begin{array}{l}\text { Specialist } \\
\text { Senior specialist } \\
\text { Administrator }\end{array}$ & $\begin{array}{r}2,885 \\
2,021 \\
252\end{array}$ & $\begin{array}{l}89.1 \\
91.7 \\
92.3\end{array}$ & 11.55 & $<0.05$ \\
\hline $\begin{array}{l}\text { Amount of professional } \\
\text { work experience }\end{array}$ & $\begin{array}{l}\text { One to five years } \\
\text { Over five years }\end{array}$ & $\begin{array}{l}1,100 \\
3,922\end{array}$ & $\begin{array}{l}88.6 \\
90.9\end{array}$ & 5.762 & $<0.05$ \\
\hline $\begin{array}{l}\text { Rate of correct responses } \\
\text { on a test of knowledge }\end{array}$ & $\begin{array}{l}\text { Less than } 60 \% \\
60 \% \text { or higher }\end{array}$ & $\begin{array}{l}1,603 \\
3,580\end{array}$ & $\begin{array}{l}82.8 \\
94.1\end{array}$ & 188.4 & $<0.05$ \\
\hline
\end{tabular}

Table 3. Univariate analysis of participants' behavior of "routinely prescribing FA tablets to women planning to become pregnant while working"

\begin{tabular}{|c|c|c|c|c|c|}
\hline Variable & Groups of responses & $\begin{array}{l}\text { Number of participants } \\
\text { with correct behaviors }\end{array}$ & $\begin{array}{l}\text { Rate of correct } \\
\text { behaviors }(\%)\end{array}$ & $\chi^{2}$ & $p$-value \\
\hline Age & $\begin{array}{l}\sim 20 \\
\sim 30 \\
\sim 40 \\
40+\end{array}$ & $\begin{array}{r}21 \\
1,227 \\
1,939 \\
1,141\end{array}$ & $\begin{array}{l}87.5 \\
76.3 \\
76.8 \\
78.7\end{array}$ & 4.287 & 0.232 \\
\hline Ethnicity & $\begin{array}{l}\text { Han } \\
\text { Other }\end{array}$ & $\begin{array}{r}3,580 \\
777\end{array}$ & $\begin{array}{l}77.9 \\
73.7\end{array}$ & 9.423 & $<0.05$ \\
\hline Level of education & $\begin{array}{l}\text { Junior high school or lower } \\
\text { Senior high school or secondary school } \\
\text { Junior college } \\
\text { Undergraduate or higher }\end{array}$ & $\begin{array}{r}133 \\
1,791 \\
1,958 \\
521\end{array}$ & $\begin{array}{l}75.6 \\
75.4 \\
78.3 \\
79.3\end{array}$ & 7.919 & $<0.05$ \\
\hline $\begin{array}{l}\text { Level of facility where } \\
\text { the participant works }\end{array}$ & $\begin{array}{l}\text { Village/community } \\
\text { Township } \\
\text { District and county } \\
\text { City } \\
\text { Province }\end{array}$ & $\begin{array}{r}47 \\
1,337 \\
2,803 \\
168 \\
35\end{array}$ & $\begin{array}{l}70.1 \\
73.7 \\
79.3 \\
74.7 \\
81.4\end{array}$ & 24.07 & $<0.05$ \\
\hline Job title & $\begin{array}{l}\text { Specialist } \\
\text { Senior specialist } \\
\text { Administrator }\end{array}$ & $\begin{array}{r}2,390 \\
1,781 \\
221\end{array}$ & $\begin{array}{l}74.6 \\
80.8 \\
81.0\end{array}$ & 31.13 & $<0.05$ \\
\hline $\begin{array}{l}\text { Amount of professional } \\
\text { work experience }\end{array}$ & $\begin{array}{l}\text { One to five years } \\
\text { Over five years }\end{array}$ & $\begin{array}{r}906 \\
3,377\end{array}$ & $\begin{array}{l}72.9 \\
78.2\end{array}$ & 15.20 & $<0.05$ \\
\hline $\begin{array}{l}\text { Rate of correct responses } \\
\text { on a test of knowledge }\end{array}$ & $\begin{array}{l}\text { Less than } 60 \% \\
60 \% \text { or higher }\end{array}$ & $\begin{array}{l}3,078 \\
1,352\end{array}$ & $\begin{array}{l}80.9 \\
69.8\end{array}$ & 89.80 & $<0.05$ \\
\hline
\end{tabular}


FA supplements $(\mathrm{OR}<1)$. Participants with a correct response rate higher than $60 \%$ were more likely to recommend $\mathrm{FA}$ than those with a rate below $60 \%$ (OR $>$ 1) (Table 5).

With an $\alpha$ of 0.05 , the variables in the regression model of the practice of "routinely prescribing FA tablet to women planning to become pregnant while working" were: ethnicity, level of education, the level of facility where the participant works, job title, professional working experience, and rate of correct responses on a test of knowledge. A higher job title and longer professional working experience resulted in a greater likelihood of routinely prescribing FA tablets to women planning to become pregnant $(\mathrm{OR}<1)$. Participants with $60 \%$ or more correct responses on the test of knowledge were more likely to routinely prescribe FA tablets to women planning to become pregnant than were those with a correct response rate below $60 \%$ (OR $>1)($ all $p<0.05)$ (Table 6).

\section{Discussion}

This study was the first attempt at a large sample study of Northern China, an area facing a high incidence of NTDs. With the help of medical personnel, this study sought to determine the KAP of obstetricians and specialists in women's health with regard to taking FA supplements in these provinces. The current results may provide valuable reference data for national interventions to reduce the incidence of NTDs and thus improve the country's health.

The Chinese Ministry of Health's "Project on birth defect interventions in six provinces of Northern China" was implemented in April 2008. The current

Table 4. Univariate analysis of participants' behavior of "usually recommending that women take FA supplements"

\begin{tabular}{|c|c|c|c|c|c|}
\hline Variable & 0 & 1 & 2 & 3 & 4 \\
\hline Behavior & True & False & & & \\
\hline Age & $\sim 20$ & $\sim 30$ & $\sim 40$ & $40+$ & \\
\hline Ethnicity & Han & Other & & & \\
\hline Level of education & Junior high school or lower & $\begin{array}{l}\text { Senior high school } \\
\text { or secondary school }\end{array}$ & Junior college & Undergraduate or higher & \\
\hline $\begin{array}{l}\text { Level of facility where the } \\
\text { participant works }\end{array}$ & Village/Community & Township & District and County & City & Province \\
\hline Job title & Specialist & Senior specialist & Administrator & & \\
\hline Professional work experience & Over five years & One to five years & & & \\
\hline $\begin{array}{l}\text { Rate of correct responses on } \\
\text { a test of knowledge }\end{array}$ & Above $60 \%$ & $60 \%$ or lower & & & \\
\hline
\end{tabular}

Table 5. Multivariate logistic regression analysis of participants' behavior of "usually recommending that women take FA supplements"

\begin{tabular}{|c|c|c|c|c|c|c|}
\hline \multirow{2}{*}{ Risk factors } & \multirow{2}{*}{$\mathrm{B}$} & \multirow{2}{*}{ S.E. } & \multirow{2}{*}{ OR } & \multicolumn{2}{|c|}{$95 \% \mathrm{CI}$ for OR } & \multirow{2}{*}{$p$-value } \\
\hline & & & & Lower & Upper & \\
\hline Constant & -3.374 & 0.350 & 0.034 & & & 0.859 \\
\hline Ethnicity & 0.198 & 0.111 & 1.219 & 0.981 & 1.515 & 0.075 \\
\hline Level of education & -0.041 & 0.069 & 0.960 & 0.838 & 1.098 & 0.549 \\
\hline Level of facility where the participant works & -0.180 & 0.082 & 0.836 & 0.711 & 0.981 & $<0.05$ \\
\hline Job title & -0.132 & 0.089 & 0.876 & 0.735 & 1.044 & 0.139 \\
\hline Amount of professional work experience & 0.161 & 0.111 & 1.174 & 0.944 & 1.461 & 0.149 \\
\hline Rate of correct responses on a test of knowledge & 1.169 & 0.096 & 3.218 & 2.664 & 3.886 & $<0.05$ \\
\hline
\end{tabular}

Table 6. Multivariate logistic regression analysis of participants' behavior of "routinely prescribing FA tablets to women planning to become pregnant while working"

\begin{tabular}{|c|c|c|c|c|c|c|}
\hline \multirow{2}{*}{ Risk factors } & \multirow{2}{*}{$\mathrm{B}$} & \multirow{2}{*}{ S.E. } & \multirow{2}{*}{ OR } & \multicolumn{2}{|c|}{$95 \% \mathrm{CI}$ for $\mathrm{OR}$} & \multirow{2}{*}{$p$-value } \\
\hline & & & & Lower & Upper & \\
\hline Constant & -1.735 & 0.244 & 0.176 & & & 0.986 \\
\hline Ethnicity & 0.125 & 0.083 & 1.133 & 0.963 & 1.332 & 0.132 \\
\hline Level of education & -0.018 & 0.048 & 0.982 & 0.894 & 1.080 & 0.713 \\
\hline Level of facility where the participant works & -0.103 & 0.058 & 0.902 & 0.805 & 1.012 & 0.078 \\
\hline Job title & -0.193 & 0.063 & 0.824 & 0.729 & 0.932 & $<0.05$ \\
\hline Amount of professional work experience & 0.201 & 0.079 & 1.223 & 1.047 & 1.429 & $<0.05$ \\
\hline Rate of correct responses on a test of knowledge & 0.618 & 0.068 & 1.856 & 1.623 & 2.121 & $<0.05$ \\
\hline
\end{tabular}


study should furnish a baseline. Since obstetricians and specialists in women's health are responsible for counseling and issuing prescriptions as part of efforts to prevent birth defects, their knowledge, level of education, and ability to serve are all relevant to the qualities of these efforts. Extremely significant is the fact that study participants included doctors who were involved in training to prevent birth defects in areas with a high incidence of NTDs. Results demonstrated that some participants were highly knowledgeable about NTDs and FA since over $80 \%$ knew that FA can be used to prevent NTDs and they knew how to correctly take FA tablets. This figure was higher than that in a 2005 survey of birth control specialists in Sichuan Province (13). Of the current participants, $69.7 \%$ knew of FA's preventive action, and $41.9 \%$ knew how to correctly take FA tablets. These results indicated that national projects to implement interventions in NTDs using FA over the past few years have greatly improved doctors' knowledge about FA and NTDs. This is especially true of doctors in regions with a high incidence of NTDs. However, there are gaps in knowledge in comparison to other countries. According to a survey of American healthcare providers from 2002 to $2003,58 \%$ of subjects knew how to correctly give FA supplements to high-risk women (14). A survey in 2004 showed that $92.3 \%$ of sixty Canadian doctors correctly answered questions about FA (15). Another study in 2002 showed that awareness of FA among 202 Indian physicians was 92.1\% (16). All of these results indicate that Chinese medical personnel in northern regions with a high incidence of NTDs still need to strive to close the gap in knowledge.

The current study showed that only $34.1 \%$ of all participants were aware of the need for women who can become or who are planning to become pregnant to take FA supplements, $34.3 \%$ knew the correct time to take FA, and $48.0 \%$ knew how to correctly give FA to women at risk of having infants with NTDs. Similar results were found in a 2008 survey in southern Israel that showed a lack of knowledge about the correct timing (12\%) of folic acid preparations for average-risk women (17). Though most of the current participants were aware that FA has a role in preventing NTDs, their knowledge about some key points such as its timing and who needed to take the supplements was lacking. Therefore, medical personnel should be educated about the need to use FA to prevent NTDs at the proper time for women who can become or who are planning to become pregnant.

Although the vast majority of participants expressed willingness to discuss the importance of FA with women of childbearing age, the reality is that only $77.2 \%$ routinely prescribed FA tablets; this may due to a lack of knowledge such as "which women should take FA supplements" and the "correct time to take FA". The 2008 survey in Israel indicated that 70 of 81 physicians
(94\%) reported routinely recommending FA to their patients (17). Thus, efforts should be made to increase awareness regarding prevention of NTD's by taking FA supplements at the proper time. Similarly, efforts must be made to educate medical personnel about correct behaviors with regard to recommending/prescribing FA supplements.

Multivariate analysis suggested that doctors in higher level hospitals were more likely to receive training, making them more likely to recommend/ prescribe FA supplements to women. Stricter working conditions also resulted in a higher rate of correct behaviors. Moreover, participants in higher positions tended to routinely prescribe FA tablets to women planning to become pregnant, which might be related to their greater amount of knowledge and working experience. Furthermore, participants with more than five years of working experience had a higher rate of correct behaviors than those with less than five years of experience, which also coincides with the results of a similar study in 2008 of 101 birth control information officers in Yunnan Province (17). Therefore, the higher rate of correct behaviors is presumably the result of combined elements of longer working experience, more experience, greater awareness of the need for relevant knowledge, and more opportunities to receive education and training. With regard to the two correctly followed practices, the number of participants who had a correct response rate of $60 \%$ on the knowledge test was respectively 3.218 and 1.856 times that of those who had a correct response rate below $60 \%$. Clearly, the level of one's knowledge plays a critical role in deciding if one's behavior is appropriate; therefore, offering training in FA and NTDs to obstetricians and specialists in women's health is especially crucial.

In general, participants had a good deal of knowledge about NTDs and FA but the lack of some knowledge possibly led to the relatively low rate of correct behaviors. The four main factors that were strongly associated with the rate of correct behaviors were found to be the level of facility where the participant works, job title, professional work experience, and the correct response rate on a knowledge test. This study also suggested that training obstetricians and specialists in women's health in NTDs and FA should have a marked effect.

\section{Acknowledgements}

This survey was supported by the National Program to Support Science and Technology (2008-2010) of China, National Project for Prevention of Child Birth Defects (Project No.: 2006BAI05A01).

\section{References}

1. Zhao XL, Ye GL, Zheng J, Chu YL, Liu Q, Cai XL. 
Effects of folic acid on the prevention of recurrent fetal NTDs. Chinese Journal of Child Health Care. 2003; 11:226-227.

2. Bower C. Fortification of food with folic acid and the prevention of neural tube defects. N Z Med J. 2003; 116: U294.

3. Oakley GP Jr. When will we eliminate folic acidpreventable spina bifida? Epidemiology. 2007; 18:367-368.

4. Iqbal MM. Birth defects: Prevention of neural tube defects by periconceptional use of folic acid and screening. J Prev Soc Med. 1999; 18:52-65.

5. Lumley J, Watson L, Watson M, Bower C. Periconceptional supplementation with folate and/or multivitamins for preventing neural tube defects. Cochrane Database Syst Rev. 2001; 3:CD001056.

6. Johansson M, Witthöft CM, Bruce A, Jägerstad M. Study of wheat breakfast rolls fortified with folic acid. The effect on folate status in women during a 3-month intervention. Eur J Nutr. 2002; 41:279-286.

7. Wilson RD, Johnson JA, Wyatt P, Allen V, Gagnon A, Langlois S, Blight C, Audibert F, Désilets V, Brock JA, Koren G, Goh YI, Nguyen P, Kapur B; Genetics Committee of the Society of Obstetricians and Gynaecologists of Canada and The Motherrisk Program. Pre-conceptional vitamin/folic acid supplementation 2007: The use of folic acid in combination with a multivitamin supplement for the prevention of neural tube defects and other congenital anomalies. J Obstet Gynaecol Can. 2007; 29:1003-1026. (in English, French)

8. Milunsky A, Jick H, Jick SS, Bruell CL, MacLaughlin DS, Rothman KJ, Willett W. Multivitamin/folic acid supplementation in early pregnancy reduces the prevalence of neural tube defects. JAMA. 1989; 262:2847-2852.

9. Berry RJ, Li Z, Erickson JD, Li S, Moore CA, Wang H, Mulinare J, Zhao P, Wong LY, Gindler J, Hong SX, Correa A. Prevention of neural-tube defects with folic acid in China. China-U.S. Collaborative Project for Neural Tube Defect Prevention. N Engl J Med. 1999; 341:1485-1490.
10. Prevention of neural tubedefects: Results of the Medical Research Council Vitamin Study. MRC Vitamin Study Research group. Lancet. 1991; 338:131-137.

11. WHO/FAO. Guidelines on Food Fortification with Micronutrients (Allen L, de Benoist B, Dary O, Hurrell R, eds.). WHO Press, Geneva, Switzerland, 2006.

12. Zeng Z, Zhu J. Low folic acid supplement intake rate among women in northern China with a highprevalence of neural tube defects, 2008. Prev Med. 2010; 51:338-339.

13. Li KS, Pu W, Zhu J. Investigation and analysis on knowledge, attitude and practice (KAP) of the folic acid supplement for prevention of neural tube defects by family planning professionals. Maternal and Child Health Care of China. 2005; 20:1008.

14. Williams JL, Abelman SM, Fassett EM, Stone CE, Petrini JR, Damus K, Mulinare J. Health care provider knowledge and practices regarding folic acid, United States, 2002-2003. Matern Child Health J. 2006; 10 (Suppl 5):S67-S72.

15. Lefebvre LG, Ordean A, Midmer D, Kahan M, Tolomiczenko G. Physicians' knowledge of alcohol, tobacco and folic acid in pregnancy. Subst Abus. 2007; 28:3-9.

16. Aggarwal A, Kumhar GD, Harit D, Faridi MM. Role of folic acid supplementation in prevention of neural tube defects: Physicians yet unaware! J Prev Med Hyg. 2010; 51:131-132.

17. Abu-Hammad T, Dreiher J, Vardy DA, Cohen AD. Physicians' knowledge and attitudes regarding periconceptional folic acid supplementation: A survey in Southern Israel. Med Sci Monit. 2008; 14:CR262CR267.

18. Su CM, Ye HF, Yuan YL, Wang JL. Investigation of the knowledge related to birth defects prevention of the workers for family planning at primary level. Chinese Primary Health Care. 2008; 22:34-36. (in Chinese)

(Received January 12, 2011; Revised April 23, 2011; Accepted May 2, 2011) 